\title{
Article
}

\section{A Two-Stage Approach to Defining an Affected Community based on the Directly Affected Population and Sense of Community}

Wylie, Rick, Haraldsen, Stephen and Howe, Joe M

Available at http://clok.uclan.ac.uk/11469/

Wylie, Rick ORCID: 0000-0002-8294-4931, Haraldsen, Stephen ORCID: 00000002-2071-1737 and Howe, Joe M (2014) A Two-Stage Approach to Defining an Affected Community based on the Directly Affected Population and Sense of Community. Journal of Risk Research, 19 (2). pp. 153-163. ISSN 1366-9877

It is advisable to refer to the publisher's version if you intend to cite from the work. http://dx.doi.org/10.1080/13669877.2014.961511

For more information about UCLan's research in this area go to http://www.uclan.ac.uk/researchgroups/ and search for <name of research Group>.

For information about Research generally at UCLan please go to http://www.uclan.ac.uk/research/

All outputs in CLoK are protected by Intellectual Property Rights law, including Copyright law. Copyright, IPR and Moral Rights for the works on this site are retained by the individual authors and/or other copyright owners. Terms and conditions for use of this material are defined in the policies page. 


\title{
A Two-Stage Approach to Defining an Affected Community based on the Directly Affected Population and Sense of Community
}

\author{
Rick Wylie
}

Applied Policy Science Unit, University of Central Lancashire, Samuel Lindow Building, Westlakes Science \& Technology Park, Moor Row, United Kingdom

Stephen Haraldsen

School of Education and Social Science, University of Central Lancashire, Westlakes Science \& Technology Park, Moor Row, United Kingdom

Joe M. Howe

Centre for Energy and Power Management, University of Central Lancashire, Preston, United Kingdom

Correspondence should be directed to Stephen Haraldsen, University of Central Lancashire, Samuel Lindow Building, Westlakes Science \& Technology Park, Moor Row, Cumbria, CA24 3JZ, email SHaraldsen@uclan.ac.uk or telephone (+44) 01964 517234. 


\section{A Two-Stage Approach to Defining an Affected Community based on the Directly Affected Population and Sense of Community}

Studies have demonstrated the inadequacy of relying on existing administrative boundaries or simple proximity to define an affected community. The proposal and siting of hazardous facilities can have a range of impacts upon people across wide areas, with some more affected than others as a result of living with the physical impacts of construction or the fear associated with perceived risk. We term those most affected the Directly Affected Population and propose a two-stage model for identifying an affected community which places those most affected at the centre of the definition. The second stage is to identify the relationships those most affected have with the wider elements of the Sense of Community to discover the existing community or communities which are affected. Illustrated by the siting of a low level radioactive waste disposal facility at Dounrey in the north of Scotland, we show that elements of the lived community experience may have very different shapes, extents and conflicting interests which pose challenges for their incorporation into a siting process. The two-stage model presented in this paper, by placing those most directly affected at the centre and working from there out into the existing communities, identifies issues early in any siting process to improve their incorporation and amelioration.

Keywords: affected community, facility siting, risk, sense of community, waste

\section{Introduction}

An effective facility siting process must embrace the community level, and a key issue in that process is defining the scope and scale of the community affected by the development and operation of a facility. However, community is a complex, contested concept and there are a number of definitions and methods for defining a community, from the ideal conception of a traditional village to 'virtual' communities where members relate remotely, perhaps only electronically by the world-wide-web. Of 
particular relevance and as a complication to defining an affected community is the observation that community can be "non-territorially based" (Heller et al 1984: 138) and socially constructed by its members (Sonn and Fisher 1996: 417). Indeed, individuals living in one location can, it is argued be members of a range of communities (Brodsky and Marx 2001; Obst and White 2007). Thus, when defining an affected community, relying on existing boundaries or arbitrary distances from a development is not sufficient (Walker 2009: 619). Extreme cases such as the development of a radioactive waste facility may have profound implications for the environment, economy and culture in its vicinity, therefore any effective definition of an affected community must move beyond physical boundaries and take into account the socio-spatial, multi-scalar implications of facility siting, within its social context.

\section{The two-stage model}

\section{The first stage - identifying the Directly Affected Population (DAP)}

The first stage towards defining an affected community requires the identification of what we term the 'Directly Affected Population' (DAP) and is, we suggest, a fundamental first stage towards a robust facility siting process. In some cases, particularly in developments near to small rural settlements and where transport routes are minimal, those directly affected may be readily apparent. In other cases, particularly for large or very controversial siting initiatives, the DAP may be identified using a technique such as risk perception mapping, which is based upon measurable psychological and social impacts (Stoffle et al 1991; Stone 2001). This would involve undertaking surveys to identify individuals who consider themselves to be 'at risk' from either an existing or proposed facility. The shape of a DAP may also take into account transportation routes associated with a facility, as well as the extent of the facility itself 
both above and below ground. Given that this is defined by perceived risk the shape and scale of this risk perception shadow may be different from that identified by probabilistic risk assessments and will be unique to the proposed facility. This then defines an 'issue community’ comprising people who share a common concern which, as we will go on to demonstrate, isn't necessarily a functioning community.

In cases where the extent of the perceived risk associated with a facility is large, or where transport routes are extensive, the DAP may potentially overlay multiple communities. The second stage of our definition of an affected community involves identifying the wider relationships the individuals in the DAP have with the elements of the lived community. In short, finding out what community those most affected are a part of, and the shape and extent of its constituent parts.

There are distinct advantages to identifying the DAP proactively, rather than arbitrarily via a distance or other criteria such as extant administrative boundaries. To conduct a satisfactory siting process, emotional responses to risk are important and need to be integrated alongside rational decision making processes (Slovic et al 2004: 311). Understanding the existing, established community of which those most affected are a part is important, particularly as "perceptions of and responses to risk and hazard are formed in the context of a range of social, cultural and political factors" (Bickerstaff 2004: 827-828) and the "politically charged clashes", which are often seen in hazardous facility siting and operation, are shaped by the local social context (Culley and Angelique 2010: 233). Early efforts to ascertain public concern and risk perception, as part of a collaborative approach to decision making, is important (Kasperson and Ram 2013: 95) especially given that perceived risk can be higher for proposed facilities than those operating (Pignataro and Prarolo 2012). 


\section{The second stage - identifying the extent of the lived community experience}

The second aspect of the definition of an affected community focuses upon the elements of the experience of living in 'a community' for members of the DAP. One of the most accepted sociological models of a community is the 'Sense of Community' (SOC) developed to unpack elements of what has been termed the 'force' or bonds which create and bind both relational and territorial communities (McMillan and Chavis, 1986; McMillan, 1996; Obst, Smith and Zinkiewicz, 2002; Obst and White, 2007; Mannarini and Fedi, 2009). Drawing upon sociological perspectives, it exposes the relationship between individuals and the communities in which they live. This wider relationship includes individuals' feelings and status of membership of a community; their emotional connection with this geographical and social space; their degree of influence, and confidence, in the governance of that place; and the ability of a locality to provide them with economic and physical resources.

Membership is based on the feeling of belonging, of sharing a sense of personal relatedness to a group, and though community has been described as a benign concept (Tuan 2002) the issue of membership can be problematic, particularly in respect of setting boundaries defining who is within and who is outside a community. Membership of a community, it is argued, gives an individual 'insider' status, a sense of belonging bestowing a valued emotional security upon an individual. It also bounds the individual to act in the interest of the wider body of the membership, an obligation of solidarity (Sandel 2009: 234). This element may be particularly salient in the siting of facilities in areas of deprivation or isolated communities, where the prospect of jobs or investment may be important to the wider community and its longer term sustainability. In such cases, opposition to a facility may be perceived as being against the interests of 
the wider community of which one is a part, and thus in extreme cases, seen or branded as a traitor by fellow members.

The Fulfilment of Needs, or reinforcement, is the feeling that membership of a group matters in terms of the receipt of resources fulfilling needs of members in return for the investing your attachment. This aspect of SOC relates in practice to a community as a sustainable economy and we equate this with the functional economic area(s) within which members of the DAP are located. It may be that members of the DAP are located within a number of functional economic areas. Identifying the wider functioning economic area within which a DAP is located is important particularly when considering sustainable benefits (compensation) packages for a host community (Evans et al 2011: 242), which intend to address the issue of social equity by off-setting disbenefit (Harrison 2004). In principle, those who are most affected should receive the most in compensation, and the 'most affected' by a siting process are the DAP, but this poses two main problems. Firstly, the use of monetary compensation can have a detrimental effect on public acceptance (Kunreuther and Easterling 1996), and in-kind compensation which doesn't have the same detrimental impact upon public acceptance (Frey et al 1996) is more suited to a wider, functioning area rather than a DAP, which may be very small or dispersed.

Integration (Political Influence) is a two-way sense of influence, whereby membership of a community is more attractive when one feels able to influence the direction of the community, but also that the group itself is strong enough to take the members with it and defend their interests (McMillan 1996: 319). In practice this may relate to political structures at a variety of scales, from local to national and supranational (e.g. the European Union). In a facility siting process the formal structures may range from local to national government and their various agencies, with differing 
roles depending on the particular facility in question. Therefore it is essential that the various formal bodies involved, and their roles, are clearly understood by all affected at an early stage particularly asthe roles may be constraining, such as the inability to use planning processes to accommodate emotional objections. Understanding such constraints should allow for issues which fall outside the scope or remit of formal processes and structures, particularly very emotional concerns, to be then separately dealt with and accommodated. It is important that, if fairness is to be achieved in facility siting, that those affected feel they are able to be involved in the process and have some possibility of affecting its outcome (Hampton 1999: 170; Schlosberg 2007: 202)

Shared Emotional Connection is based on a shared culture, history and common symbols, perhaps including shared understanding of significant events (which does not necessarily have to be experienced personally/first-hand). This aspect of the community experience can be especially problematic, requiring a careful approach to its identification, articulation and accommodation in a siting process. For the purposes of facility siting the emotional element of community is broadly equated with a sense of place (Relph 1974), which we take as a particular geographical space that has meaning to an individual or a group often, but not exclusively, as a consequence of residence over time. It has been argued that there are three key components to a sense of place, the physical characteristics of the environment, the activities afforded by the place, including social interactions, and the affect and meanings, including memories and associations, as well as connotations and denotations associated with the place (Turner and Turner 2006: 207).

In short, these definitions provide an insight into the elements constituting a functioning community as a place to live and to work. The shape and spatial extent of 
these aspects of the lived and experienced community are not necessarily contiguous, and may each have a different geography which does or does not conform with existing or traditional conceptions of community or administrative structures. In addition, depending on its geography a DAP may cover multiple of the same elements of what constitutes a community, such as straddling multiple administrative areas. The paper will now turn to illustrating the elements of this model by exploring the siting of a lowlevel radioactive waste disposal facility adjacent to the Dounreay nuclear site near Thurso at the very northern edge of Scotland, UK.

\section{Buldoo and the Dounreay Low Level Waste Repository}

\section{Background and methodology}

The decommissioning and demolition of UK nuclear sites will create a shortfall in capacity for the disposal of radioactive waste, and consequently new sites are needed (DEFRA 2007; NDA 2010). While currently most low level wastes go to the national repository in Cumbria, Scottish Government policy effectively ended the transport of radioactive wastes (SEPA 2007). This has led to the need for new storage and disposal sites to handle the wastes from the decommissioning of Scottish nuclear facilities, such as the Dounreay fast-reactor research site, near Thurso, on the northern Scottish coast (see Map 1). The process to find a site the low level waste (LLW) arising from the decommissioning of the Dounreay site began in the early 2000s, with a Best Practicable Environmental Option (BPEO) study (Broughton 2004), which identified a near surface site adjacent to the existing Dounreay site boundary. Following the BPEO, a planning application was made to the Highlands Council in 2008 for six concrete vaults and 
associated infrastructure, to be constructed in three phases, with permission being granted in April 2009.

The Dounreay LLW facility siting provided a rare, live radioactive waste siting case-study to explore the applicability of the two-stage model. Semi-structured interviews were conducted over a three-day period from $26^{\text {th }}$ to the $29^{\text {th }}$ August 2009 with the people personally and professionally most closely involved with the siting process. Given the isolated location, most of those people closely involved with the siting process after the BPEO were interviewed. The first group was with the members of the Buldoo Residents' Association, who are the Directly Affected Population. The second group was with members of the Dounreay Stakeholder Group, which included the staff from the Dounreay site, local residents, business owners and councillors, which covered the wider community interests. The third interview was with a senior member of staff from the Highland Council, which is the planning authority. 


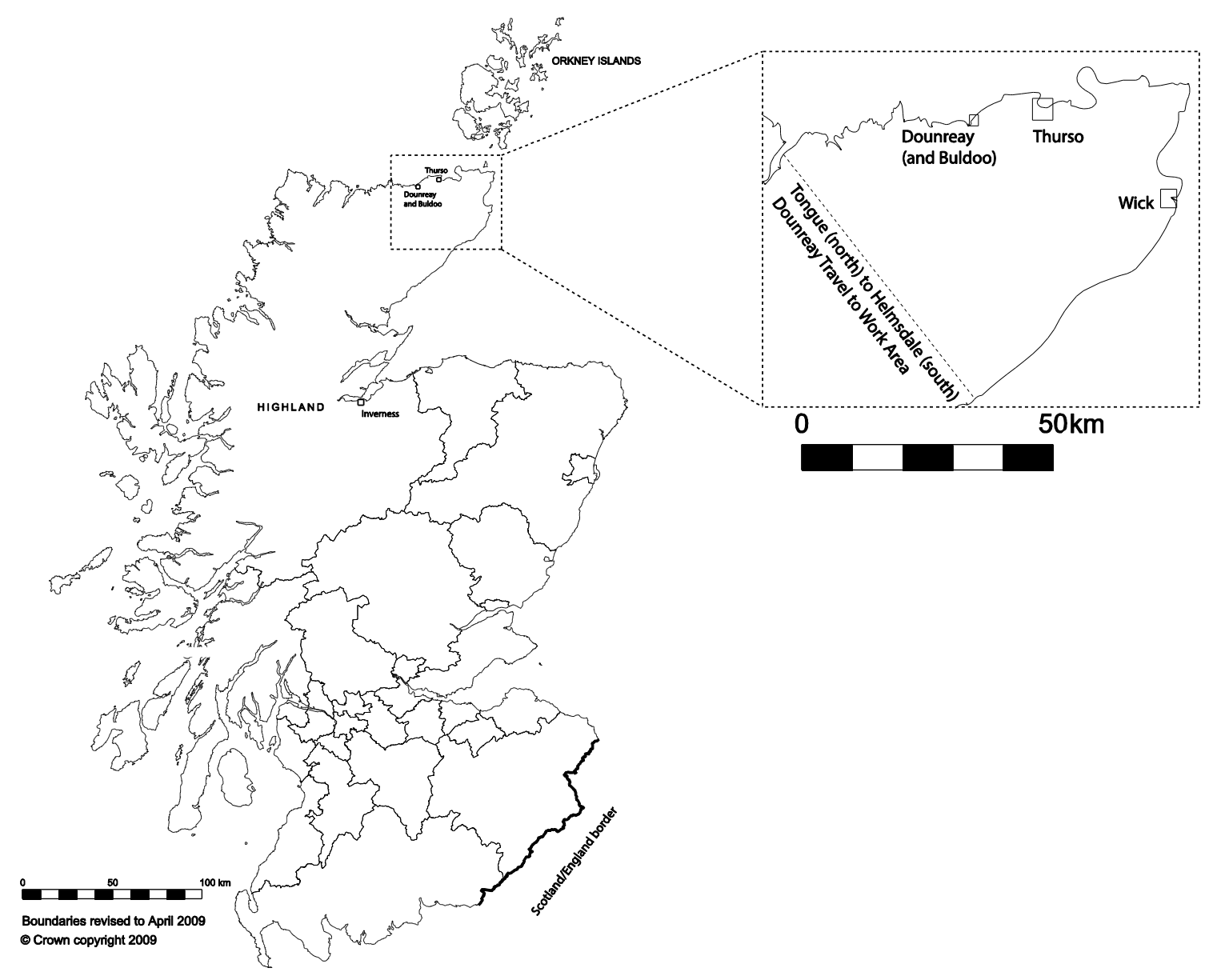

Figure 1. Scotland and the location of Dounreay

\section{The DAP and its relationship with the community}

In this case, the DAP had self-identified, through the formation of a group, the 'Buldoo Residents' Association'. This was aided by the location of the Dounreay site, like many nuclear sites, being fairly remote even by the standards of the sparsely populated northern parts of Scotland. Buldoo, a hamlet directly adjacent to the existing Dounreay site and proposed waste facility, is the only settlement nearby. Buldoo is comprised of only a small group of houses and farms which look out onto the Dounreay site and the location of the waste disposal site, less than one kilometre away. The key issues this siting raised were that it was outside the existing Dounreay site boundary, 
and that the plans were presented as a fait accompli to the residents. This made the planning process effectively the sole remaining outlet to challenge the proposal, however the formal and adversarial nature of planning, coupled with the emotional nature of opposition, made this outlet problematic. Opposing the scheme led to tensions within the wider community between those directly affected and the wider community which was amplified by the late provision of community benefits.

Membership of a community places an obligation upon members to act in its interests. Perhaps unsurprisingly in this case, where the local economy is heavily dependent on the industry in question, the issue of obligation was salient to the siting of the repository. In the remote or isolated communities around large nuclear sites such as at Dounreay, the "nuclear oases" (Blowers 2003) which are economically dependent on the nuclear industry and where the site is part of the cultural history there can be an assumption that all members support nuclear developments, and that they should not bite the hand that feeds them. However, despite the effect of proximity, where the site becomes more a part of the sense of place and perceived risk decreases the closer one lives to a site (Venables et al 2012: 372) support for the nuclear industry, and acceptance of radiological risks, does not mean that more 'mundane' concerns associated with construction, like location, noise, nuisance and so on will be automatically tolerated (Haraldsen et al 2011).

At Buldoo, where the DAP had spoken out strongly against specific details of the proposed waste repository, they felt that members of the wider Thurso community of which Buldoo and Dounreay are a part did not recognise the difference between taking issue with a proposal, and attacking an industry on which the area relies:

"If you're not saying good things about Dounreay, you're treated like a traitor" (DAP participant) 
This feeling of not being welcome in their own community was felt by residents of the DAP to be put into practice by the local body charged with publicly holding the Dounreay site to account, the Dounreay Stakeholders Group (DSG). Members of the DAP were invited to sit on the group as a formal route to air issues with the proposed low level waste facility development, but no longer felt comfortable at the stakeholder group for opposing the repository scheme. One participant from the DAP branded it the “Dounreay Supporters Group”. This status of insider and outsider became yet more salient when the potential benefits of a facility were considered, in particular the issue of compensation.

Members of the DAP adjacent to the Dounreay nuclear facility were well aware that the economic aspect of their community experience at Buldoo was embedded in the much wider Travel to Work Area (TTWA) of the Dounreay site, covering a large area from Tongue in the north west to Helmsdale in the south east (see Map 1). The residents' recognised that their tiny hamlet of Buldoo, while very dear emotionally to them, could not survive without its relationships with the wider economic area. In recognising that the DAP is not a functional, sustainable community, residents believed that compensation should strengthen the wider economic area of which they were a part. However, the compensation package did have the potential to exacerbate issues of membership and loyalty, with wider community interests acutely aware of the decline in jobs at Dounreay in the medium and long term, which made the opposition to the siting by Buldoo residents further reason to see them as either against an opportunity for jobs and investment, and not concerned about problems facing the wider area.

In turn, the residents of Buldoo believed that some residents further afield only showed an interest or concern after announcement of community benefits for the facility, and that: 
"The wider communities are in it for what they can get".

\section{(DAP Participant)}

Initial rejection of any form of benefits, followed by a later change of stance by the site owners and operators at Dounreay potentially exacerbated this perception of people further afield showing a late interest only once money was on the table. The propensity for hazardous, particularly nuclear, facilities to be in sparsely populated areas and the obvious power of economic incentives in such areas may not have a diverse job market, the scope and scale of economic benefits of a project must be outlined early. Identifying the functional economic area, such as the Dounreay Travel to Work Area in this case, is essential and then the needs of both the DAP and members of the functional economic community can be ascertained and negotiation on any mitigation or benefits can begin early.

The effect of scale in relation to elements of the sense of community and the DAP may be important. At Dounreay, the waste repository was driven by national policy both at UK and Scottish level, and subject to planning permission and control by local government. In this case at Dounreay, local government is not necessarily particularly local. The Highland council covers the widest area of any council in the UK and is headquartered over 100 miles away (see Figure 1) in Inverness. In many cases the local decision makers won't be so remote, but other agencies may be, such as regulatory bodies and other agencies of central government which may be involved in a siting process. The number of agencies involved, and their remoteness, led to the members of the DAP at Buldoo struggling to ascertain where power lay in the process, and simply referred to it as "the controlling mind". In attempting to voice their concerns to whomever held power members of the DAP wrote to everyone from Councillors to Members of Parliament in Scotland, London and Europe, and even 
member of the Royal Family. In many ways this was exacerbated by the fact plans were drawn up then presented to the wider community, after a specific site was chosen, in what members of the DAP called a "fait accompli" rather than involving those most affected in the selection of options, making the process seem at best opaque and at worse purposely secretive. Indeed, in the case of Buldoo, changes to the plans were made to move the site slightly, which could have been avoided had agencies engaged members of the DAP proactively and early.

The role of formal structures and processes, and the tensions between them and a DAP are highlighted in this case by the formal planning permission processes of the Highland Council, and some of the very emotional, place-based concerns the DAP had regarding the site chosen. The waste facility at Dounreay has been developed on what was previously undeveloped farm land, which had particular, very personal meanings for some individuals living immediately adjacent to the facility, as a result of their family and friends living on and having access to the land associated with the facility for many years. The loss was strongly with a resident noting that:

"I don't take my children down there because I don't want them to know it [so they won't miss the area when it is fenced off]".

\section{(DAP participant)}

These residents had a deep emotional connection and were concerned that a "large part of our way of life [is being] taken away from us and our children..." (Grant 2010), yet they could not figure out why when there was ample land within the existing site boundary.

The technical and rational nature of formal planning processes, operating within very rigid policy both national and local, make incorporating emotional concerns into formal processes difficult (Owens 2004: 103). Additionally, even if it isn't the case 
with a local government as it was for the Highland Council and Buldoo, some agencies are likely to be remote and not sensitive to these local concerns. This rigidity of process, which one member of the DAP described as "adversarial", does not suit the articulation of emotional and place-based attachments and concerns, nor does it recognise them as material considerations when granting or denying planning permission. If those most affected had been consulted prior to the development of the repository plans such a strong reaction against encroachment onto 'virgin' land may have been expected and dealt with in a manner more appropriate than at a planning meeting in which such emotional concerns are dismissed as not being material or relevant.

\section{Summary}

We have proposed a two-stage approach to defining an affected community in respect of hazardous facility siting, drawing upon both individual and relational aspects of community to firstly identify an issue community or Directly Affected Population (DAP) and secondly to identify the membership, political, economic and emotional elements of the lived community experience of members of the DAP. Each of these elements of the lived community experience may be differently spatially scaled (MacKinnon 2010: 21), with some actors will operating at different scales simultaneously (Kirby 2002: 171).

At the very local level identity, priorities, objectives and action will all be shaped by culture and place attachment, drawing upon and acting for the narrow range of conditions of that small area. The threat that a hazardous facility poses to the members of the DAP is real given that emotional attachment with a place impacts heavily the value placed upon it (Slovic et al 2004: 318), therefore emotional responses to the siting of unwanted or hazardous land uses should be expected as protective 
actions based on an attachment to place (Devine-Wright 2009: 432),particularly as hazardous facilities, especially those dealing with radioactive waste, can be terrifying for those directly affected (Ruckelshaus 1984). Though it would seem sensible to use existing democratic structures to incorporate such issues, a DAP is an issue community and so 'shape' of a DAP will be distinctive to the issue. It may be that neither the extent of a DAP, or most elements of the lived community experience for members of a DAP, coincide with existing administrative areas. An effective siting process must allow for the emergence of issue communities or DAPs within wider administrative jurisdictions. This is especially so where administrative bodies covering broad areas make claims to speak on behalf of a community, yet whose jurisdictions cover a wide area and contain within them a diversity of relationships with a facility. One of the key requirements in the siting of a hazardous facility is the ability to accommodate different perspectives on, and framings of, a particular issue (Bull et al 2010). The inclusion of emotional, place-based concerns in decision making alongside other, sometimes competing elements, such as economic concerns, is a challenge. The tensions which can arise when rational planning and administrative processes find accommodating competing emotional and economic concerns difficult can be damaging to the community, pitting members against each other in an 'adversarial' planning processes.

The most obvious potential limitation of the current study is the small sample size for the case study. In this case while the sample included all those most directly affected and closely involved in the siting process, which is due to the very small size of the population of the directly affected area of Buldoo. Future work could seek to employ a quantitative methodology in the first stage to identify the DAP. In the UK the on-going siting process the deep geological disposal of higher activity radioactive wastes would allow for a more extensive testing of the model for a large scale facility 
for very hazardous and emotive waste products. Nevertheless, the study reported here included all those most directly affected by the first successful radioactive waste facility sitiing in Britain for over 50 years. This has demonstrated that the proactive identification of those most directly affected, and then through them the wider affected community (or elements of multiple communities) allows for potentially problematic issues to be discovered, rather than being left to emerge unexpectedly. Placing the concerns of these most affected at the centre of any siting process is vital to ensure an equitable outcome, but at the same time not ignoring the potentially wide ranging impacts of a facility by identifying the elements of the lived community experience and their unique issues and extents.

\section{Acknowledgements}

\section{Funding}

This paper reports on research conducted in pursuance of a European 6th Framework Contract [FP6/036455] supported by the Nuclear Decommissioning Authority in the UK. 


\section{References}

Bickerstaff, K. (2004) Risk perception research: socio-cultural perspectives on the public experience of air pollution $30827-840$

Blowers, A. (2003) Inequality and Community and the Challenge to Modernization: Evidence from the Nuclear Oases, in Agyeman, J., Bullard, R.D. and Evans, B. (eds.) Just Sustainabilities: Development in an Unequal World. London. Earthscan.

Brodsky, A. E. and Marx, C. M. (2001). Layers of identity: Multiple psychological senses of community within a community setting. Journal of Community Psychology 29 (2) 1-18.

Broughton, D. (2004) Dounreay LLW Strategy Development Best Practicable Environmental Option Study Final Report. UKAEA Report GNGL(04)TR75

Bull, R., Petts, J. and Evans, J. (2010) The importance of context for effective public engagement: learning from the governance of waste. Journal of Environmental Planning and Management 53 (8) 991-1009

Culley, M.R. and Angelique, H. (2010) Nuclear Power: Renaissance or Relapse? Global Climate Change and Long-Term Three Mile Island Activists' Narratives. American Journal of Community Psychology 45 (3-4) 231-246

DEFRA (2007) Policy for the Long Term Management of Solid Low Level Radioactive Waste in the United Kingdom [Accessed 06 December 2010, available online at:http://www.decc.gov.uk/assets/decc/what\%20we\%20do/uk\%20energy\%20supply/ene rgy\%20mix/nuclear/radioactivity/llw-policystatement070326.pdf] 
Devine-Wright, P. (2009) Rethinking NIMBYism: The Role of Place Attachment and Place Identity in Explaining Place-protective Action. Journal of Applied Social Psychology 19 426-441

Evans, B., Parks, J. and Theobald, K. (2011) Urban wind power and the private sector: community benefits, social acceptance and public engagement. Journal of Environmental Planning and Management 54 (2) 227-244

Frey, B.S., Oberholzer-Gee, F. And Eichenberger, R. (1996) The Old Lady Visits Your Backyard: A Tale of Morals and Markets. Journal of Political Economy 104(6) 1297-1313

Grant, I. (08 October 2010) Dump work ‘invading’ Buldoo residents. John O’Groat Journal [Accessed 06 December 2010, available on-line at: http://www.johnogroatjournal.co.uk/news/fullstory.php/aid/8751/Dump_work_invading_Buldoo_residents.h $\mathrm{tml}]$

Hampton, G. (1999) Environmental equity and public participation. Policy Sciences 32: 163-174

Haraldsen. S., Wylie, R. and Howe, J.M. (2011) When Nuclear is Normal. Nuclear Futures 7 (6): 42-45.

Harrison, N.E. (2004) Constructing Sustainable Development. Albany, NY; State University of New York Press.

Heller, K., Price, R.H., Reinharz, S., Riger, S., Wandersman, A. and D’Aunno, T.A. (1984) Psychology and Community Change: Challenges for the Future. Monterey, Brooks/Cole. 
Kasperson, R.E. and Ram, B.J. (2013) The Public Acceptance of New Energy Technologies. Dædalus - Journal of the American Academy of Arts and Sciences 142 (1): $90-96$

Kunreuther, H. and Easterling, D. (1996) The role of compensation in siting hazardous facilties. Journal of Policy Analysis and Management 15(4) 601-622

Kirby, A. (2002) Popular Culture, Academic Discourse, and the Incongruities of Scale in Herod, A. and Wright, M.W. (2002 eds.) Geographies of Power: Placing Scale. Oxford, Blackwell.

MacKinnon, D. (2010) Reconstructing scale: Towards a new scalar politics. Progress in Human Geography 35 (1) 21-36

Mannarini, T. and Fedi, A. (2009) Multiple Senses of Community: The Experience and Meaning of Community. Journal of Community Psychology 37(2) 211227

McMillan, D.W. (1996) Sense of Community. Journal of Community Psychology 24 (4) 315325.

McMillan , D.W. and Chavis, D.M. (1986) Sense of Community: A Definition and Theory. Journal of Community Psychology, 14. 6-23.

NDA (2010) UK Strategy for the Management of Solid Low Level Radioactive Waste from the Nuclear Industry [Accessed 06 December 2010, available on-line at http://www.nda.gov.uk/documents/upload/UK-Strategy-for-the-Management-of-SolidLow-Level-Radioactive-Waste-from-the-Nuclear-Industry-August-2010.pdf] 
Obst, P., Smith, S.G. and Zinkiewicz, L. (2002) An Exploration of Sense of Community, Part 3: Dimensions and Predictors of Psychological Sense of Community in Geographical Communities. Journal of Community Psychology 30 (1) 119-133.

Obst, P.L. and White, K.M. (2007) Choosing to Belong: The Influence of Choice on Social Identification and Psychological Sense of Community. Journal of Community Psychology 35 (1) 77-90.

Owens, S. (2004) Siting, sustainable development and social priorities. Journal of Risk Research 7 (2) 101-114

Pignataro, G. and Prarolo, G. (2012) One More in My Backyard? Insights from the 2011 Italian Nuclear Referendum (June 28, 2012). Quaderni DSE Working Paper No. 837. Available at SSRN: http://ssrn.com/abstract=2095054 or http://dx.doi.org/10.2139/ssrn.2095054

Relph, E. (1974) Place and Placelessness. London, Pion.

Ruckelshaus, W.D. (1984) The Role of the Affected Community in Superfund Cleanup Activities. Hazardous Waste 1(3) 283-288. 050105/05 Page A2 of 2 Final Issue WSC 7 January 2010

Sandel, M. (2009) Justice: What's the right thing to do? London, Penguin.

Schlosberg, D. (2007) Defining Environmental Justice: Theories, Movements, and Nature. Oxford; Oxford University Press.

SEPA (2007) Dounreay Low Level Waste Facilities Project Outline [Accessed 28 February 2011, available on-line at: 
http://www.sepa.org.uk/radioactive_substances/decommissioning/dounreay/idoc.ashx?d ocid=0b9e476c-b853-4ec8-a4e2-719a9ac0d48d\&version=-1]

Slovic, P., Finucane, M.L., Peters, E. and MacGregor, D.G. (2004) Risk as Analysis and Risk as Feeling: Some Thoughts about Affect, Reason, Risk, and Rationality 24(2) 311-322

Stoffle, R.W. et al (1991) Risk Perception Mapping Using Ethnography to Define the Locally Affected Population for a Low-Level Radioactive Waste Storage Facility in Michigan. American Anthropologist 93 (3) 611-635.

Stone, J.V. (2001) Risk Perception Mapping and the Fermi II nuclear power plant: toward an ethnography of social access to public participation in Great Lakes environmental management. Environmental Science and Policy, 4 205-217.

Sonn, C.C. and Fisher, A.T. (1996) Psychological Sense of Community in a Politically Constructed Group. Journal of Community Psychology 24 (2) 417-430.

Tuan, Y. (2002) Community, Society, and the Individual. Geographical Review 92 (3) 307-318.

Turner, P. and Turner, S. (2006) Place, Sense of Place and Presence. Presence 15 (2) 204-217.

Venables, D., Pidgeon, N.F., Parkhill, K.A., Henwood, K.L. and Simmons, P. (2012) Living with nuclear power: Sense of place, proximity, and risk perceptions in local host communities. Journal of Environmental Psychology 32 (4): 371-383

Walker, G. (2009) Beyond Distribution and Proximity: Exploring the Multiple Spatialities of Environmental Justice. Antipode 41(4) 614-636 